\title{
PENGETAHUAN TENTANG KARIES GIGI SEBELUM DAN SESUDAH PENYULUHAN KESEHATAN DI PERGURUAN ADVENT CIMINDI BANDUNG
}

\author{
KNOWLEDGE OF DENTAL CARIES BEFORE AND AFTER HEALTH \\ EDUCATION IN PERGURUAN ADVENT CIMINDI BANDUNG
}

\section{Mesrina Simbolon ${ }^{1}$, Imanuel Sri Mei Wulandari²}

Fakultas IImu Keperawatan, Universitas Advent Indonesia

Email: mesrinasimbolon@gmail.com

\begin{abstract}
ABSTRAK
Pendahuluan: Hasil studi pendahuluan yang dilakukan peneliti kepada kepada 10 orang siswa/i kelas 4 SD di Perguruan Advent Cimindi Bandung, mereka tidak mengetahui apa itu karies gigi dan apa yang menyebabkannya bahkan 5 orang dari antara mereka mengalami karies gigi. Tujuan: Penelitian ini bertujuan untuk mengetahui sejauh mana pengetahuan tentang karies gigi di Perguruan Advent Cimindi Bandung. Metode: Desain penelitian yang digunakan dalam penelitian ini adalah desain peneitian kuantitatif dengan rancangan pra-post tes dalam satu kelompok (pra-post test design). Penelitian ini dilakukan di Perguruan Advent Cimindi Bandung pada 31 Oktober 2017. Populasi dalam penelitian ini adalah seluruh siswa/i kelas 4 di Perguruan Advent Cimindi Bandung tahun ajaran 2017/2018. Pengambilan sampel yang digunakan dalam penelitian ini adalah sampling jenuh. Jumlah sampel dalam penelitian ini adalah 43 orang. Data dikumpul menggunakan tes yang terdiri dari 12 pertanyaan dengan nilai validasi dan reabilitas. Nilai validasi antara 0,446-0,707 dan nilai reabilitas adalah 0,859 . Data yang terkumpul kemudian diolah dengan menggunakan rumus persentasi dan uji hipotesis dengan pengujian dua pihak menggunakan SPSS. Hasil: Hasil perhitungan menunjukkan bahwa pengetahuan tentang karies gigi sebelum penyuluhan kesehatan adalah cukup dengan angka persentasi $74,4 \%$. Pengetahuan setelah penyuluhan adalah baik dengan angka persentasi $92,7 \%$. Hasil perhitungan thitung menunjukkan bahwa terdapat perbedaan yang signifikan pengetahuan tentang karies gigi di Perguruan Advent Cimindi Bandung sebelum dan sesudah penyuluhan kesehatan dengan nilai thitung 5,920 pada taraf kepercayaan $95 \%$ atau $\alpha=0,05$. Diskusi: Beberapa saran ditujukan kepada praktik keperawatan komunitas, pendidikan keperawatan komunitas, dan penelitian selanjutnya.
\end{abstract}

Kata kunci: Pengetahuan, Karies gigi

\section{ABSTRACT}

Introduction: Results of a preliminary study conducted by researchers at the 10 students 4th grade in Cimindi Bandung Adventist University, they do not know what it is dental caries and what causes, even 5 of them experienced dental caries.Purpose: This study aims to determine the extent of knowledge about dental caries in Cimindi Bandung Adventist University. Method: The research design used in this research is quantitave design with pre-post test in one group (pre-post test design). This research was conducted in Cimindi Bandung Adventist University on October 31, 2017. The population in this study were all students grade 4 in Perguruan Advent Cimindi academic year 2017/2018. Sample used in this study is total sampling. The number of samples in this study were 43 people. Data was collected using a test consisting of 12 questions with the validation value and reliability. Validation value between 0.446 to 0.707 and the value of reliability is 0.859 . The collected data is then processed using a percentage formula and hypothesis testing by paired t-test using SPSS. Result: The calculations result show that knowledge about dental caries before health education is enough with the percentage $74.4 \%$. Knowledge after health education is good with percentage $92.7 \%$. The results of this study showed a significant differences in knowledge about dental caries in Perguruan Advent Cimindi Bandun before and after health education with $t$-count 5.920 at $95 \%$ level confidence or $\alpha=0.05$. Discussion: Several suggestions were addressed to nursing community practice, nursing community education and nursing research. 


\section{PENDAHULUAN}

Pembangunan kesehatan merupakan bagian terpenting dalam mencapai tujuan pembangunan nasional. Tujuan pembangunan kesehatan adalah untuk meningkatkan kesadaran, kemauan dan kemampuan hidup sehat bagi setiap orang agar terwujud derajat kesehatan masyarakat yang optimal. Keberhasilan pembangunan kesehatan memegang peran penting dalam meningkatkan mutu dan daya saing sumber daya manusia Indonesia. Pencapaian tujuan pembangunan kesehatan ditempuh dengan menyelenggarakan berbagai upaya kesehatan secara menyeluruh, berjenjang, dan terpadu (Depkes RI, 2015).

Pelayanan kesehatan gigi dan mulut merupakan bagian integral dari pelayanan kesehatan secara menyeluruh. Indikator status kesehatan gigi dan mulut telah ditetapkan yang mengacu pada Global Goals for Oral Health 2020 yang dikembangkan oleh FDI dan WHO. Salah satu program teknis yang disarankan adalah agar negara-negara di dunia mengembangkan kebijakan pencegahan penyakit gigi dan mulut serta meningkatkan upaya promosi kesehatan gigi dan mulut, khususnya pada anak usia sekolah dan remaja (Kemenkes RI, 2012).

Penyakit gigi dan mulut yang menjadi masalah kesehatan masyarakat pada umumnya adalah penyakit/kelainan pada jaringan penyangga gigi (periodontal diseases) dan karies gigi. Hal ini sebenarnya mudah dicegah yaitu dengan menanamkan kebiasaan/perilaku pemeliharaan kesehatan gigi yang baik sejak usia dini (Depkes, 2015). Penyakit gigi yang sering diderita oleh hampir semua penduduk Indonesia ialah karies gigi (Riskesdas, 2013).

Prevalensi karies masih cukup tinggi di seluruh dunia, ini berdasarkan Federation Dentaire Internationale (2013) yaitu sekitar $90 \%$ penduduk dunia berisiko mengalami penyakit gigi dan mulut. World Health Organization (2012) juga mengemukakan bahwa di dunia sekitar 60-90\% dari anak usia sekolah mengalami karies gigi.

Di Amerika Serikat, karies gigi merupakan penyakit kronis anak-anak yang sering terjadi dan tingkatnya 5 kali lebih tinggi dari asma (Healthy People, 2010). Karies merupakan penyebab patologi primer atas penanggalan gigi pada anak-anak (American Dental Hygiene Association, 2010). Anak usia 12 tahun merupakan usia di mana karies akan lebih cepat terjadi karena gigi molar/geraham merupakan gigi dimana makanan mudah melekat karena bentuk anatominya (WHO, 2012).

Hampir semua provinsi di Indonesia mengalami peningkatan jumlah penderita karies gigi. Peningkatan tertinggi terdapat di Provinsi Sulawesi Selatan $(29,1 \%)$ dan Lampung $(23,6 \%)$, yaitu dua kali lebih peningkatan Nasional $(9,8 \%)$. Bila di tinjau dari kelompok umur menurut WHO, penderita karies aktif mengalami peningkatan prevalensi dari tahun 2007 ke tahun 2013, dengan peningkatan terbesar pada usia 12 tahun $(13,7 \%)$ (Riskesdas, 2013). 
Data perilaku menggosok gigi pada masyarakat Indonesia terjadi peningkatan dari tahun 2007 ke tahun 2013 dari 91,1\% menjadi 93,8\%. Tetapi, jika dilihat dari data masyarakat Indonesia yang menggosok gigi dengan benar memiliki prevalensi yang kecil bahkan mengalami penurunan yaitu 7,3\% pada tahun 2007 menjadi 2,3\% pada tahun 2013. Penurunan ini terjadi di semua provinsi yang ada di Indonesia dengan penurunan yang sangat drastis di Provinsi Kepri $(15,4 \%)$ dan provinsi Papua Barat $(14,7)$ (Info Dokter, 2015).Hasil Pemeriksaan Kesehatan Dasar (2013) menunjukkan sebanyak 12,04 juta warga Jawa Barat atau 28\% dari total 43 juta penduduk di provinsi itu mengalami masalah kesehatan gigi dan mulut. Angka ini termasuk tinggi dan memerlukan perhatian khusus agar prevalensinya tiak meningkat lagi.

Dari latar belakang ini penulis ingin memberikan penyuluhan kesehatan tentang karies gigi dan membandingkan pengetahuan mereka pada saat sebelum penyuluhan kesehatan dan sesudah penyuluhan kesehatan.

\section{METODE PENELITIAN}

Penelitian ini dilakukan untuk mengetahui sejauh mana pengetahuan tentang karies gigi sebelum dan sesudah penyuluhan kesehatan. Populasi dalam penelitian ini adalah seluruh siswa/i kelas 4 SD di Perguruan Advent Cimindi Bandung tahun ajaran 2017/2018 yang berjumah 43 orang. Desain penelitian yang digunakan adalah desain peneitian kuantitatif dengan rancangan pra-post tes dalam satu kelompok (One-group pra-post test design). Jumlah responden sebanyak 43 orang. Dengan pengambilan sampel secara total sampling.
Penelitian ini dilakukan di Perguruan Advent Cimindi Bandung pada tanggal 31 Oktober 2017. Penilaian pengetahuan sebelum dan sesudah penyuluhan kesehatan dilakukan dengan menggunakan test yang berisi 12 pertanyaan tentang karies gigi. Test terlebih dahulu di uji validitas dan releabilitas agar layak digunakan dalam penelitian. Nilai validasi antara 0,4460,707 dan nilai reabilitas adalah 0,859 .

Peneliti mengukur tingkat pengetahuan dilakukan sebanyak dua kali yaitu sebelum peneliti memberikan penyuluhan kesehatan dan setelah penyuluhan kesehatan. Hasil test pengetahuan sebelum dan sesudah penyuluhan kesehatan akan dianalisa dengan menggunakan rumus persentasi pengetahuan dan diinterpretasikan sesuai dengan skala pengetahuan menurut Arikunto (2006). Skor 76\%-100\% kategori baik, skor 56\%-75\% kategori cukup, skor $<56 \%$ kategori kurang. Untuk mengetahui perbedaan pengetahuan sebelum dan sesudah pengetahuan akan dilakukan uji hipotesis dengan pengujian dua pihak dengan taraf signifikansi $\alpha=0,05$.

\section{HASIL}

Tabel 1. Rata-rata Persentasi Pengetahuan Sebelum dan Sesudah penyuluhan

\begin{tabular}{|c|c|c|c|c|c|}
\hline \multicolumn{6}{|c|}{ Paired Samples Statistics } \\
\hline & & Mean & $\mathrm{N}$ & Std. Deviation & $\begin{array}{l}\text { Std. Eror } \\
\text { Mean }\end{array}$ \\
\hline Pair & PRE & 74,4186 & 43 & 14,70559 & 2,24258 \\
\hline 1 & POST & 91,6674 & 43 & 12,20690 & 1,86153 \\
\hline
\end{tabular}

Tabel 1. menunjukkan bahwa persentasi pengetahuan tentang karies gigi di Perguruan Advent Cimindi Bandung sebelum diberikan peyuluhan kesehatan adalah 74,4\%. Arikunto (2006) 
mengatakan bahwa persentase pengetahuan $74,4 \%$ berada pada kategori cukup. Sedangkan presentasi pengetahuan sesudah diberikan penyuluhan kesehatan adalah 91,66\%, dimana ini menunjukan nilai pada kategori baik. Hasil yang didapatkan adanya peningkatan dari kategori cukup sebelum diberikan penyuluhan dan kategori baik sesudah diberikan penyuluhan.

Ada beberapa faktor yang dapat memengaruhi pengetahuan seseorang salah satunya adalah sarana komunikasi / media massa (Notoadmodjo, 2010). Sarana komunikasi dan berbagai bentuk media massa seperti televisi, radio, surat kabar, majalah, dan internet mempunyai pengaruh besar terhadap pembentukan opini dan kepercayaan orang. Media massa baik cetak maupun elektronik akan memberikan berbagai informasi sehingga masyarakat akan memperoleh informasi yang lebih banyak dan dapat memengaruhi pengetahuan seseorang (Notoadmodjo, 2010).

Pengetahuan yang baik diperlukan agar masyarakat mau dan dapat melakukan anjuran yang berhubungan dengan kesehatan (Maulana, 2009). Hal ini menunjukkan bahwa pengetahuan tentang miopi masih perlu ditingkatkan. Salah satu metode yang dapat digunakan untuk meningkatkan pengetahuan adalah melalui penyuluhan.

Penyuluhan kesehatan adalah kegiatan pendidikan dengan cara menyebarkan pesan, menanamkan keyakinan pada masyarakat sehingga masyarakat sadar, tahu, mengerti, dan bisa melakukan sutau imbauan yang berhubugan dengan kesehatan. Tujuan dari pemberian penyuluhan kesehatan adalah untuk meningkatkan pengetahuan, kesadaran, kemauan, dan kemampuan masyarakat dan agar menciptakan hidup sehat masyarakat juga berperan aktif dalam upaya kesehatan (Ali, 2010).

Tabel 1. menunjukkan bahwa persentasi pengetahuan tentang karies gigi di Perguruan Advent Cimindi Bandung sesudah diberikan peyuluhan kesehatan adalah 92,7 \%. Arikunto (2006) mengatakan bahwa persentase pengetahuan $92,7 \%$ berada pada kategori baik. Hasil data di atas menunjukkan bahwa pengetahuan tentang karies gigi sesudah penyuluhan kesehatan berada pada kategori baik. Peningkatan pengetahuan ini menunjukkan bahwa penyuluhan kesehatan dengan metode ceramah tentang miopi adalah metode yang efektif untuk meningkatkan pengetahuan. Pengetahuan dapat diperoleh melalui mendengarkan materi yang disajikan dengan gambar dan penjelasan dalam bentuk power point menggunakan media LCD.

Hasil penelitian ini sejalan dengan penelitian yang dilakukan oleh Wijayanti (2016) yang menyimpulkan bahwa ceramah dengan power point menggunakan media LCD dapat meningkatkan pengetahuan. Mahfoedz (2007) menambahkan faedah penggunaan media yakni mendorong keinginan orang untuk mengetahui, kemudian lebih mendalami, dan akhirnya memberikan pengertian yang lebih baik.

Hal ini juga didukung oleh Notoadmodjo (2010) yang mengatakan bahwa penyuluhan atau pendidikan kesehatan adalah suatu kegiatan atau usaha untuk menyampaikan pesan kepada masyarakat, kelompok atau individu. Diharapkan dengan adanya pesan tersebut akan mempertahankan pengetahuan yang sudah baik dan 
meningkatkan pengetahuan yang kurang.

Maulana (2009) menyatakan bahwa penyuluhan merupakan pendidikan kesehatan yang dilakukan dengan menyebarkan pesan dan menanam keyakinan. Hal ini dimaksudkan agar masyarakat tidak saja sadar, tahu, dan mengerti, tetapi mau dan dapat melakukan anjuran yang berhubungan dengan kesehatan.

Tabel 2. Perbedaan Pengetahuan Sebelum dan Sesudah Penyuluhan

Paired Samples Test

\begin{tabular}{|c|c|c|c|c|c|c|c|c|}
\hline & \multicolumn{5}{|c|}{ Paired Differences } & \multirow[b]{3}{*}{$t$} & \multirow[b]{3}{*}{$d f$} & \multirow[b]{3}{*}{ Sig. (2-tailed) } \\
\hline & \multirow[b]{2}{*}{ Mean } & \multirow[b]{2}{*}{ Std. Deviation } & \multirow{2}{*}{$\begin{array}{l}\text { Std. Error } \\
\text { Mean }\end{array}$} & \multicolumn{2}{|c|}{$\begin{array}{l}95 \% \text { Confidence } \\
\text { Interval of the } \\
\text { Difference }\end{array}$} & & & \\
\hline & & & & Lower & Upper & & & \\
\hline $\begin{array}{ll}\text { Pair } 1 & \text { Pre-Post }\end{array}$ & $-2,070$ & 2,293 &, 350 & $-2,775$ & $-1,364$ & $-5,920$ & 42 & ,000 \\
\hline
\end{tabular}

Berdasarkan hasil olah data tersebut, diketahui bahwa hasil $\mathrm{t}_{\text {hitung }}$ adalah 5,920 dan $t$ tabel 1.68195. Menurut Sugiyono (2008), pada kriteria pengujian dua pihak, bila $\mathrm{t}$ hitung $<\mathrm{t}$ tabel maka Ho diterima dan harga $\mathrm{t}$ hitung adalah harga mutlak, jadi tidak dilihat (+) dan (-), dengan demikian 5,920 >1,68195, maka $\mathrm{t}$ hitung $>\mathrm{t}$ tabel. Berarti nilai Ho ditolak dan nilai Ha diterima dengan signifikan pada taraf kepercayaan 95\%, nilai $\propto$ $0,050, \mathrm{dk}=\mathrm{n}-1=43-1=42$. Oleh sebab itu dari hasil di atas dapat disimpulkan bahwa ada perbedaan yang signifikan pengetahuan tentang karies gigi di Perguruan Advent Cimindi Bandung sebelum dan sesudah penyuluhan kesehatan.

Hasil dari data di atas menunjukkan bahwa ada perbedaan yang signifikan antara pengetahuan tentang karies gigi sebelum dan sesudah penyuluhan kesehatan. Hal tersebut memperlihatkan bahwa penyuluhan yang disampikan peneliti memberikan pengaruh terhadap peningkatan pengetahuan tentang karies gigi.

Hal ini sesuai dengan pendapat Notoadmodjo (2010) yang mengatakan bahwa penyuluhan atau pendidikan kesehatan adalah suatu kegiatan atau usaha untuk menyampaikan pesan kepada masyarakat, kelompok atau individu. Diharapkan dengan adanya pesan tersebut akan mempertahankan pengetahuan yang sudah baik dan meningkatkan pengetahuan yang kurang. Hasil ini juga sejalan dengan hasil penelitian Ayuningsih (2014) yang menyimpulkan bahwa penyuluhan kesehatan berpengaruh terhadap pengetahuan dan sikap. Penyuluhan kesehatan yang diberikan kepada siswa akan meningkatkan pengetahuan mereka tentang penyuluhan kesehatan yang diberikan.

Kahmir (2008) menyatakan bahwa penyuluhan merupakan metode yang efektif untuk meningkatkan pengetahuan. Penyuluhan lebih efektif untuk meningkatkan pengetahuan karena dalam mengikuti penyuluhan selain membaca, peserta penyuluhan dapat mendengarkan penjelasan materi.

\section{SARAN}

Beberapa saran ditujukan untuk pendidikan keperawatan komunitas, 
praktik keperawatan komunitas, dan penelitian keperawatan. Hasil penelitian yang diperoleh diharapkan dapat dijadikan sumber acuan bagi perawat dalam melakukan penyuluhan kesehatan tentang karies gigi kepada anak sekolah. Penelitian ini diharapkan dapat menambah pemahaman mengenai penyuluhan kesehatan tentang miopi untuk anak sekolah sehingga memperkaya ilmu pengetahuan dalam bidang keperawatan khususnya mata kuliah keperawatan komunitas.

Hasil penelitian ini diharapkan dapat dijadikan referensi atau masukan bagi peneliti lain yang ingin melakukan penelitian yang lebih lanjut tentang pengetahuan karies gigi dan perilaku pencegahan karies gigi di Perguruan Advent Cimindi Bandung.

\section{DAFTAR PUSTAKA}

Ali, M. (2007). Ilmu dan Aplikasi Pendidikan. Bandung: PT IMTIMA

Arikunto, S. (2006). Prosedur Penelitian Suatu Pendekatan Praktek. Jakarta: Rineka Cipta. 344

Arikunto, S. (2013). Prosedur Penelitian Suatu Pendekatan Praktik. Jakarta: Rineka Cipta

Data Karie. (2015) 93 Juta Lebih Penduduk Indonesia Menderita Karies Akif. (22 Maret 2017)

Departemen Kesehatan RI. (2004). Pedoman Rujukan Upaya Kesehatan Gigi. Jakarta.

Federation Dentaire Internationale. (2013). FDI's definition of Oral Health. http://www.fdiworlddental.org/ (22 Maret 2017).

Kahmir. (2008). Promosi Kesehatan dan Ilmu Prilaku. Bandung: Alpabeta

Kementerian Kesehatan RI. (2015). Promosi Kesehatan di Daerah Bermasalah Kesehatan. Jakarta

Kompas. (2016). Mengapa Sikat Gigi Perlu Diganti 3 Bulan Sekali. http://lifestyle.kompas.com/read/ 2016/02/24/161600923/Mengap a.Sikat.Gigi.Perlu.Diganti.3.Bula n.Sekali. (04 April 2017)

Mahfoedz, I. (2007). Pendidikan kesehatan bagian dari promosi kesehatan. Yogyakarta: Fitramaya

Maulana. H. D. J. (2009). Promosi Kesehatan. Jakarta: EGC

Nasir (2009). Menjaga Kesehatan Gigi dan Mulut. Alfabeta: Bandung

Notoadmodjo, S. (2010). Metodologi Penelitian Kesehatan. Jakarta: Rineka Cipta

Notoadmodjo. S. (2007). Promosi Kesehatan dan Ilmu Perilaku. Jakarta: Rineka Cipta

Notoadmodjo. S. (2012). Metodologi Penelitian Kesehatan. Jakarta: Rineka Cipta

Nursalam. (2013). Metodologi Penelitian Ilmu Keperawatan. Jakarta: Salemba Medika. Ed. 3

Riduwan. (2008). Dasar-dasar Statistik. Bandung: Alfabeta 
Riset Kesehatan Dasar. (2007). Badan Penelitian Dan Pengembangan Kesehatan Departemen Kesehatan RI. Jakarta

Riset Kesehatan Dasar. (2013). Badan Penelitian Dan Pengembangan Kesehatan Departemen Kesehatan RI. Jakarta

Riset Kesehatan Dasar. (2013). Badan Penelitian Dan Pengembangan Kesehatan Kementerian Kesehatan RI. Jakarta
Sugiyono. (2008). Metode Penelitian Kuantitatif Kualitatif. Bandung: Alfabeta

Sugiyono. (2012). Metode Penelitian Kuantitatif Kualitatif. Bandung: Alfabeta

Sumijatun. (2012). Membudayakan Etika dalam Praktik Keperawatan. Jakarta: Salemba Medika.

Wirartha. (2007). Pedoman Penulisan Usulan Penelitian, Skripsi, danTesis. Yogyakarta: Andi 